\title{
Temperature Values Variability in Piezoelectric Implant Site Preparation: Differences between Cortical and Corticocancellous Bovine Bone
}

\author{
Luca Lamazza, ${ }^{1}$ Girolamo Garreffa, ${ }^{2,3}$ Domenica Laurito, ${ }^{1}$ \\ Marco Lollobrigida, ${ }^{1}$ Luigi Palmieri, ${ }^{4}$ and Alberto De Biase ${ }^{1}$ \\ ${ }^{1}$ Department of Oral and Maxillofacial Sciences, Sapienza University of Rome, 00161 Rome, Italy \\ ${ }^{2}$ Euro-Mediterranean Institute of Science and Technology, 90139 Palermo, Italy \\ ${ }^{3}$ Me. Di. Mediterranea Diagnostica, 80053 Castellammare di Stabia, Italy \\ ${ }^{4}$ National Centre of Epidemiology, Surveillance, and Promotion of Health, National Institute of Health, 00161 Rome, Italy \\ Correspondence should be addressed to Marco Lollobrigida; marcolollobrigida@gmail.com
}

Received 27 November 2015; Accepted 31 January 2016

Academic Editor: David M. Dohan Ehrenfest

Copyright (c) 2016 Luca Lamazza et al. This is an open access article distributed under the Creative Commons Attribution License, which permits unrestricted use, distribution, and reproduction in any medium, provided the original work is properly cited.

Purpose. Various parameters can influence temperature rise and detection during implant site preparation. The aim of this study is to investigate local temperature values in cortical and corticocancellous bovine bone during early stages of piezoelectric implant site preparation. Materials and Methods. 20 osteotomies were performed using a diamond tip (IM1s, Mectron Medical Technology, Carasco, Italy) on two different types of bovine bone samples, cortical and corticocancellous, respectively. A standardized protocol was designed to provide constant working conditions. Temperatures were measured in real time at a fixed position by a fiber optic thermometer. Results. Significantly higher drilling time (154.90 sec versus $99.00 \mathrm{sec} ; p<0.0001)$ and temperatures $\left(39.26^{\circ} \mathrm{C}\right.$ versus $34.73^{\circ} \mathrm{C} ; p=0.043$ ) were observed in the cortical group compared to the corticocancellous group. A remarkable variability of results characterized the corticocancellous blocks as compared to the blocks of pure cortical bone. Conclusion. Bone samples can influence heat generation during in vitro implant site preparation. When compared to cortical bone, corticocancellous samples present more variability in temperature values. Even controlling most experimental factors, the impact of bone samples still remains one of the main causes of temperature variability.

\section{Introduction}

Thermal trauma has been widely recognized as one potential cause of osteonecrosis following bone surgical procedures [1, 2]. In the specific field of dental implants, thermal injury has also been reported to cause early implant failure [3]. Most in vitro studies have thus addressed bone viability after thermal trauma [4]. Although different threshold values are reported in the literature [5-7], a temperature of $47^{\circ} \mathrm{C}$ for 1 minute is the most commonly accepted value to avoid bone injury [8]. In other words, thermal damage to bone is related to the magnitude of the temperature elevation and the duration of exposure.
Several factors contribute to temperature elevation during implant site preparation [9] but little is known about the specific contribution of each individually. Factors conducive to temperature elevation can be divided into three main groups: technique-, operator-, and bone-related factors. With respect to conventional drilling, technique-related factors include drill speed, cutting efficiency, and the cooling system. Applied load and motion pattern are to be related to operator. Despite efforts to standardize all the parameters involved during in vitro experiments, the anisotropic thermal behavior of bone introduces an additional factor that can have a major impact on temperature variation. Focusing on bone specimens, distinct features can thus be considered, that is, 
animal species, sample macrogeometry, cortical-medullary ratio, cortical thickness, bone mineral density (BMD), and thermal conductivity. Moreover, it is difficult to investigate the effect of one class of variables while maintaining constant other parameters.

More recently, use of piezoelectric devices has been proposed for implant site preparation [10, 11]. Selective and micrometric cut and bleeding control by cavitation effects are the main advantages of piezoelectric bone surgery $[12,13]$. Histologic findings also showed good response of bone tissue after piezoelectric surgery compared to conventional techniques [14]. The use of piezoelectric technique for implant site preparation seems to positively affect osseointegration and implant stability [15] when compared to the traditional drilling technique. However, as in rotating techniques, a number of factors contribute to temperature elevation including technique-related factors (e.g., tip geometry and surface, internal or external irrigation), operatorrelated factors (applied load and motion pattern), and bonerelated factors. Although piezoelectric technique has been shown to be reliable and effective, to date less data are available on local temperature rise, as the vast majority of studies published on the topic have been conducted using rotating techniques. Moreover, certain results variability has been observed in previous studies. The aim of this in vitro study has been to investigate local temperature values in cortical and corticocancellous bone samples during the early phases of piezoelectric implant site preparation. The primary question has been whether temperature variability could be related to bone specimens. The secondary question has been whether differences exist in temperature and osteotomy duration between the groups. A standardized protocol using a mechanical guiding device was adopted to control both technique and operating parameters.

\section{Materials and Methods}

2.1. Test Description. A total of 20 osteotomies at a depth of $10 \mathrm{~mm}$ were performed using a diamond tip (IM1s, Mectron Medical Technology, Carasco, Italy) (Figure 1) in two different groups of bovine bone samples, cortical and corticocancellous, respectively. Corticocancellous specimens consisted of sectioned ribs of young bovine (Figure 2(a)), while cortical samples consisted of split shaft sections of the femur (Figure 2(b)). Both samples were collected from the same animals. A novel mechanical device was used to guarantee constant working conditions (Figure 3(a)). By the action of micrometer screws, bone samples and drill were moved in the three major axes in order to create the holes for the thermometer sensors. The piezoelectric handpiece was mounted on a transmission tool, equipped with handle, for both vertical and rotational manual movement. These movements were executed by a single expert operator. Temperatures were measured in real time and recorded using a fiber optic thermometer (Luxtron m 3300 Biomedical Lab Kit, Luxtron Corporation, Santa Clara, CA, United States). The detection point was first set at $0.5 \mathrm{~mm}$ from the tip surface, $8 \mathrm{~mm}$ from the tip head. Each bone sample was then

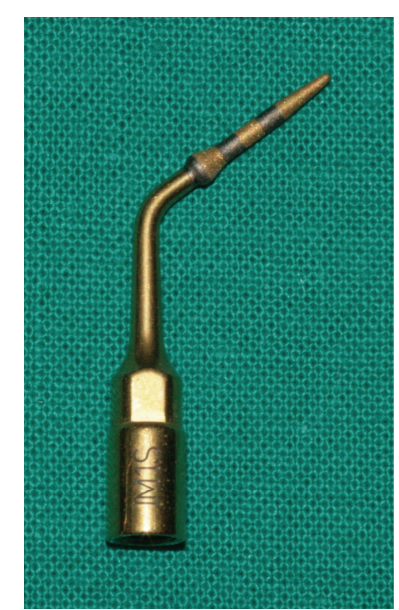

Figure 1: The diamond tip (IM1s, Mectron Medical Technology, Carasco, Italy) used in the tests. This tip can be regarded as a pilot drill in piezoelectric implant site preparation.

moved so that the detection point was $2 \mathrm{~mm}$ below the top of the specimen (Figure 3(b)). Real time data were displayed on a screen using dedicated software (TrueTemp, LumaSense Technologies, Inc., Santa Clara, CA, United States). Three variables were considered for data analysis:

(i) $T_{\max }\left({ }^{\circ} \mathrm{C}\right)$ : maximum temperature reached during the test;

(ii) $T_{60}\left({ }^{\circ} \mathrm{C}\right)$ : mean temperature on a $60 \mathrm{sec}$ time interval around $T_{\max }\left(30 \mathrm{sec}\right.$ before and $30 \mathrm{sec}$ after each $T_{\max }$ value);

(iii) duration (sec): number of seconds from the first tipto-bone contact till a drilling depth of $9 \mathrm{~mm}$ was reached.

A load cell equipped with display showed the real time load applied on bone. The working load was maintained under $150 \mathrm{gr}$. Working cycles of $4 \mathrm{sec}$ were adopted, as described in an earlier study [16]. Each cycle consisted of three different movements: longitudinal downward, rotational, and longitudinal upward. Bone samples were kept wet at all times, stored frozen in saline at $-10^{\circ} \mathrm{C}$, and used within 3 to 4 weeks. Osteotomies were performed at room temperature $\left(24-26^{\circ} \mathrm{C}\right)$ with a baseline temperature of $20 \pm 1.5^{\circ} \mathrm{C}$.

2.2. Statistical Analysis. In order to investigate the temperature rise at our test point in the two different bone samples, mean, standard deviation, and median of the variables of duration, $T_{\max }$, and $T_{60}$ were elaborated according to bone sample group. Correlation analysis was also performed on the variables. Given the number of samples, the MannWhitney nonparametric $U$ test for independent samples was performed so as to compare the average duration, $T_{\max }$, and $T_{60}$ between the two groups; the test of median was used for comparing medians; Levene's test using $F$-Fisher values was used for comparison of variances. Statistical significance was accepted at $p=0.05$. The size of 10 osteotomies for each of the two samples assures a statistical power over 


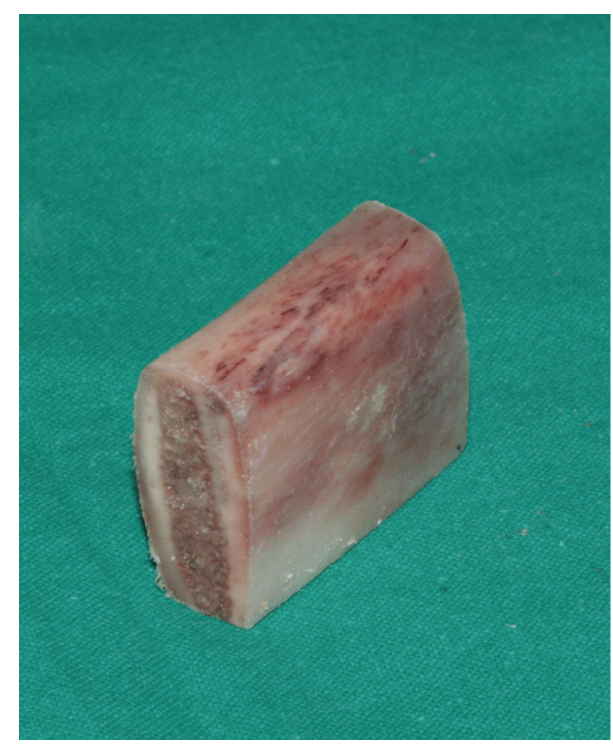

(a)

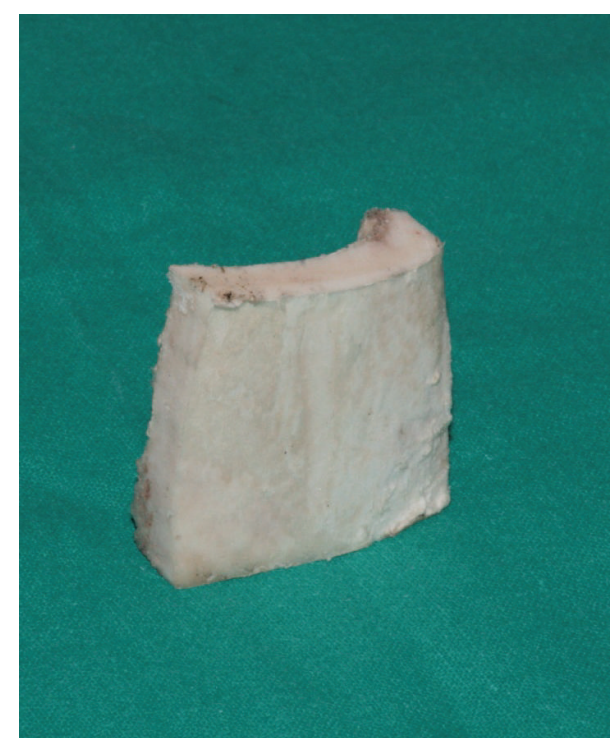

(b)

Figure 2: The two types of bone samples used in the tests. (a) Corticocancellous bone. (b) Cortical bone.

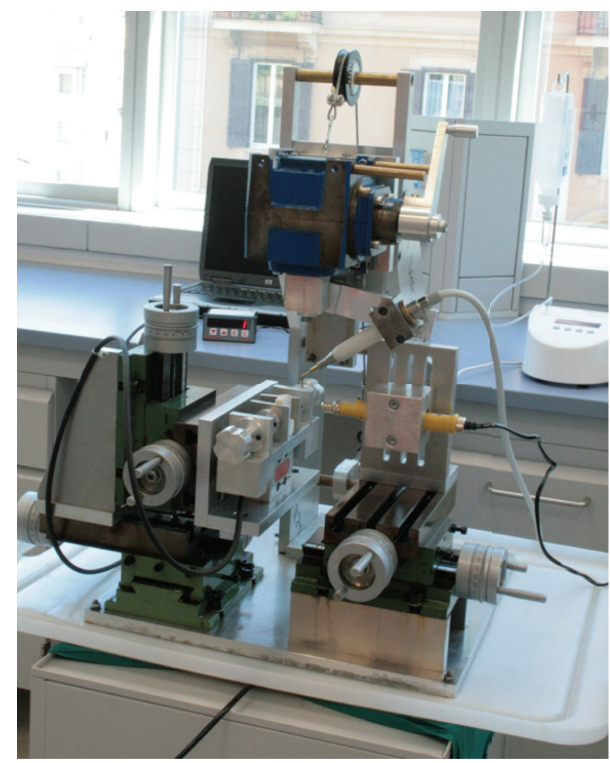

(a)

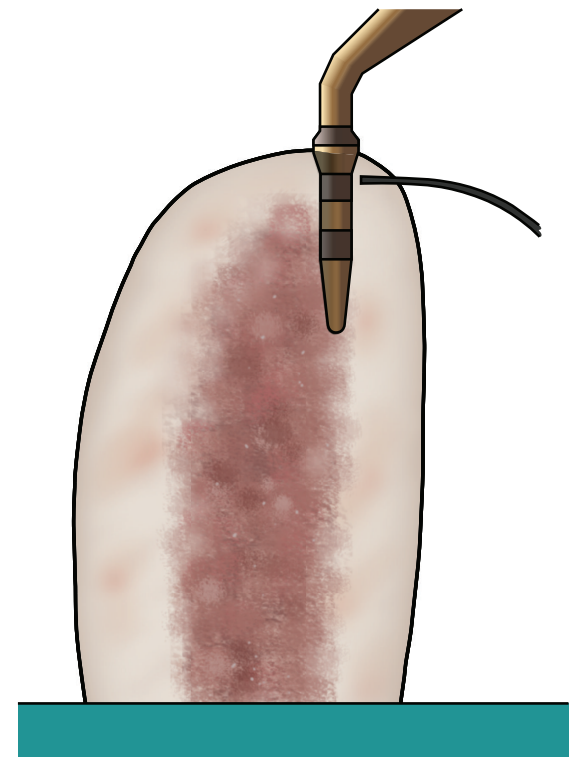

(b)

Figure 3: (a) The mechanical positioning device used in the study. By rotating the micrometric screws, a reproducible distance of $0.5 \mathrm{~mm}$ between the thermometer probe and the tip within the bone samples was obtained. Also visible, the drill (yellow-colored) used to prepare the holes for the thermometer probes. (b) Schematic section of a bone sample (corticocancellous) with the thermometer probe and the tip at completion of drilling.

$80 \%$ in the comparison of the mean values of duration and temperature between the two independent groups of bone samples under the hypothesis that variables were normally distributed, given the standard deviations and the differences calculated in each group and given the type 1 error probability of 0.05 associated with the null hypothesis that the population means of the two groups were equal.

\section{Results}

Tables 1 and 2 report the summary statistics for each variable of duration, $T_{\max }$, and $T_{60}$ with nonparametric tests results for mean and median comparison.

Osteotomies had an average duration that was significantly higher $(p<0.0001)$ in cortical bone than in 
TABle 1: Means, standard deviations, and comparison of means using Mann-Whitney $U$ test for duration, $T_{\max }$, and $T_{60}$, in the two bone samples.

\begin{tabular}{lccccc}
\hline & \multicolumn{2}{c}{ Cortical } & \multicolumn{2}{c}{ Corticocancellous } & \multicolumn{2}{c}{ Mann-Whitney $U$ test } \\
& Mean & SD & Mean & SD & 11.7 \\
\hline Duration $(\mathrm{sec})$ & 154.90 & 12.7 & 99.00 & 8.0 & $<0.0001$ \\
$T_{\max }\left({ }^{\circ} \mathrm{C}\right)$ & 44.06 & 2.4 & 40.07 & 5.2 & 0.089 \\
$T_{60}\left({ }^{\circ} \mathrm{C}\right)$ & 39.26 & 2.3 & 34.73 & 0.043 \\
\hline
\end{tabular}

TABle 2: Medians and comparison of medians using the test of median for duration, $T_{\max }$, and $T_{60}$ in the two bone samples.

\begin{tabular}{lccc}
\hline & $\begin{array}{c}\text { Cortical } \\
\text { Median }\end{array}$ & $\begin{array}{c}\text { Corticocancellous } \\
\text { Median }\end{array}$ & $\begin{array}{c}\text { Test of median } \\
p \text { value }\end{array}$ \\
\hline Duration $(\mathrm{sec})$ & 149.50 & 98.50 & $<0.0001$ \\
$T_{\max }\left({ }^{\circ} \mathrm{C}\right)$ & 43.46 & 39.04 & 0.179 \\
$T_{60}\left({ }^{\circ} \mathrm{C}\right)$ & 38.85 & 36.11 & 0.656 \\
\hline
\end{tabular}

corticocancellous bone ( $154.90 \mathrm{sec}$ versus $99.00 \mathrm{sec}$ ). Similar results were found for medians, with statistically significant $(p<0.0001)$ higher values for the cortical group $(149.50 \mathrm{sec}$. versus $98.50 \mathrm{sec}$ ). Means and medians of $T_{\max }$ were higher in the cortical bone sample group than in the corticocancellous group ( 44.06 versus $40.07^{\circ} \mathrm{C}$ and 43.46 versus $39.04^{\circ} \mathrm{C}$, resp.) but the differences were not statistically significant $(p=$ 0.089 and $p=0.179$, resp.). On the contrary, $T_{60}$ values resulted in being significantly higher in the cortical bone group $\left(39.26^{\circ} \mathrm{C}\right.$ versus $\left.34.73^{\circ} \mathrm{C} ; p=0.043\right)$; median values proved higher in the cortical bone sample group than in the corticocancellous samples, but these differences were not statistically significant. A graphical representation of the data is provided in Figure 4.

As reflected by standard deviations, the temperature values resulted in being less dispersed in the cortical group: the dispersion of $T_{\max }$ values was about three times higher in the corticocancellous group than in the cortical group (8.0 versus 2.4 , resp.). As for $T_{60}$, standard deviation was about double (5.2 versus 2.3, resp.). In addition, the $F$-Fisher test for comparison of variances was statistically significant for both $T_{\max }(F=6.484 ; p=0.020)$ and $T_{60}(F=9.663 ; p=0.006)$ confirming a different variability in the two groups (Table 3 ).

Test duration presented a positive correlation with $T_{\max }$ ( $\rho=0.404)$, even if not statistically significant $(p=0.077)$, and with $T_{60}(\rho=0.604 ; p=0.005)$ (data analysis not reported).

\section{Discussion}

Bone necrosis related to high temperatures is a well-known phenomenon observed in differing surgical specialties [17]. Up to now, most of the research concerning heat generation during bone surgery has involved in vitro studies [18]. A number of methods have been developed to investigate various techniques of bone instrumentation, for example, traditional drilling, ultrasound, and laser devices. However, since different factors play specific roles in each technique, a comprehensive and unique approach to the study of heat generation in bone tissue has not been developed as yet [19]. Furthermore,
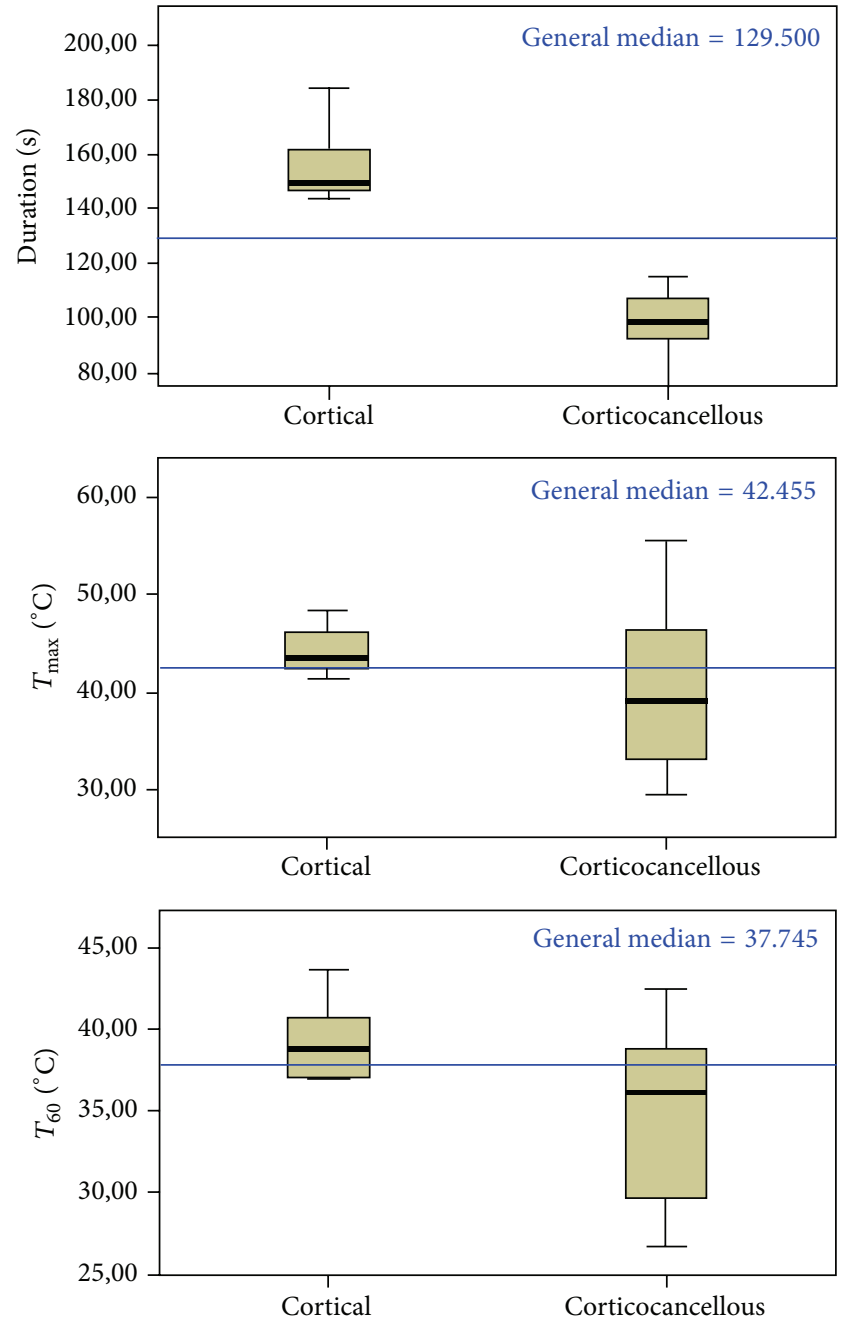

FIgURE 4: Box plots graphs showing the distribution of values for variables of duration, $T_{\max }$, and $T_{60}$. Overall median values (continuous horizontal lines), specific median values by the two bone samples (continuous horizontal lines in the boxes), and ranges (whiskers) are shown. Statistically significant differences between the two bone samples median values were found for duration and $T_{60}$ variables only.

the use of bone samples from different animal species makes it difficult to compare studies generating different results. In the present study, by using a mechanical positioning device, the technical and operator-related factors were controlled, thus focusing the analysis on bone thermal response.

From our results, no statistically significant differences were found for $T_{\max }$ values between the groups, while mean 
TABLE 3: $F$-Fisher values and statistical significance ( $p$ value) for variance comparison between the two bone samples using Levene's test for duration, $T_{\max }$, and $T_{60}$.

\begin{tabular}{lcc}
\hline & $F^{*}$ & Sig. \\
\hline Duration $(\mathrm{sec})$ & 0.10 & 0.75 \\
$T_{\max }\left({ }^{\circ} \mathrm{C}\right)$ & 6.48 & 0.02 \\
$T_{60}\left({ }^{\circ} \mathrm{C}\right)$ & 9.66 & 0.006 \\
\hline
\end{tabular}

${ }^{*}$ Equal variances assumed.

temperature and osteotomy duration resulted in being significantly higher in the cortical group. Remarkably, different results were obtained depending on temperature parameters $\left(T_{\max }\right.$ and $\left.T_{60}\right)$, with lower values and statistically significant difference between the groups only for the $T_{60}$ values. As it is shown in Figure 5, temperature values present different trends in the two groups; peaks too are differently scattered along the timeline. Moreover, temperature peaks show different shapes, indicating different relevance. In fact, a high but abrupt temperature rise in the context of an overall low thermal response may have less relevance than a moderate but protracted temperature rise. This suggests that $T_{\max }$ alone cannot be regarded as a reliable indicator of bone thermal response in this kind of test, in which temperature is affected by specific bone characteristics. By contrast, mean temperature around the maximum may be more representative of overall bone thermal response. As evidenced in the graphs cited above, bone thermal response would seem to be less smooth in the cortical group.

Apparent disorder in the cortical group is, however, a result of peak distribution along the timeline. Conversely, the wider vertical distribution of temperature peaks in the corticocancellous group reveals the variability of thermal behavior as reflected by the analysis of variance. These findings suggest that heterogeneous bone samples are characterized by a wider variability in measured temperature values during ultrasonic implant site preparation.

Variable results may therefore be related to specimens and to experimental errors [20], despite the great effort expended in this study to minimize the latter. If, on the one hand, it is proven that conventional drilling in cortical bone produces higher temperature than in cancellous bone [21, 22], less is known about the intrinsic thermal behavior of different kinds of bone specimens. Bone is commonly considered as thermally anisotropic [23-25]. However, Davidson and James [26] concluded that bovine cortical bone can be considered as thermally isotropic. Regardless of differences in test conditions, it can be argued that the variability of results found in the corticocancellous group derives from differences in cortical thickness and from the structural complexity of cancellous bone (mineral composition, fluid dynamics, trabecular orientation, etc.).

From a microscopic viewpoint, BMD seems an important feature in determining bone thermal response. Karaca et al. [27] reported a positive correlation between BMD and temperature rise using samples from bovine tibia. The authors specify that temperatures were recorded at a distance of $0.5 \mathrm{~mm}$ from the hole drilled but did not clarify the probe's
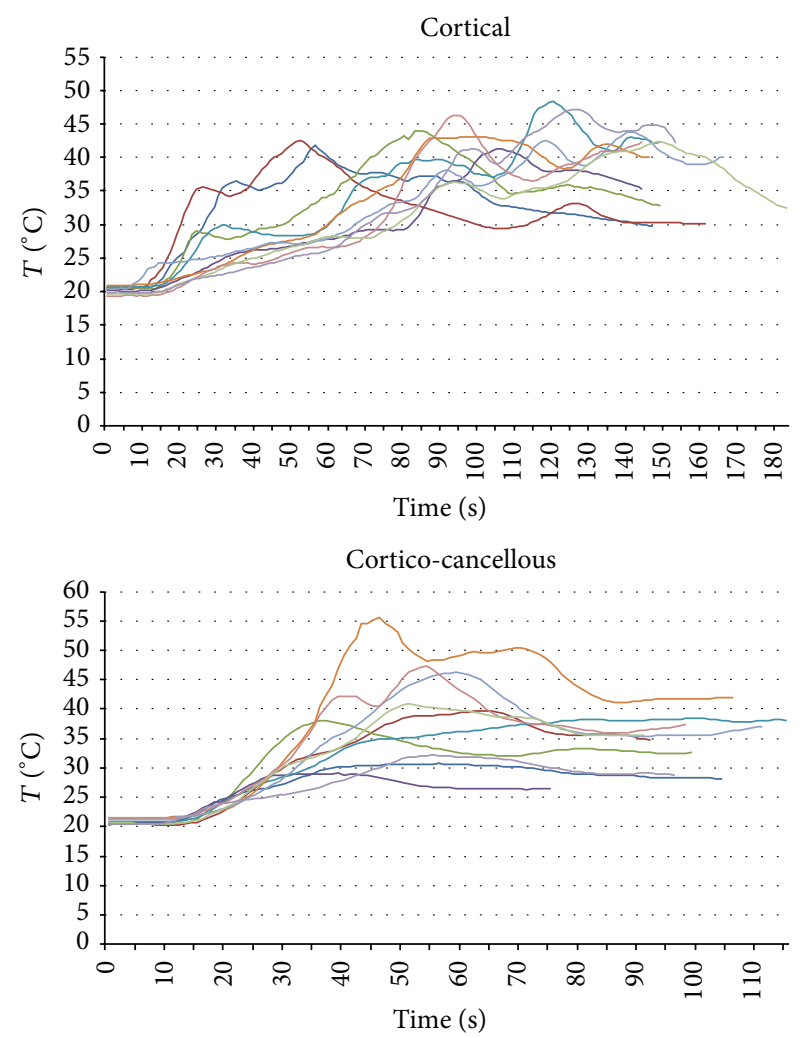

FIGURE 5: Comprehensive graphs showing temperature trends in cortical and corticocancellous bone samples.

exact location (cortical or medullary). Although BMD is expected to be higher in the cortical layer, bone hardness can differ from one sample to another, as well as in different sites of the same specimen. Clearly, the greater the cortical thickness, the greater the "cortical" effects on temperature rise. Sener et al. [28] reported higher temperatures in cortical bone than in cancellous bone with conventional drilling techniques. However, only one type of bone samples (fresh bovine mandibles) was used in this study, basing the distinction between cortical and cancellous bone on the depth of the probe. Similarly, Rashad et al. [29] found higher temperatures in cortical bone during ultrasonic preparation. Yet these results are not directly comparable with other studies since data from multiple tips were pooled. Stelzle et al. [30] compared piezoelectric implant site preparation with conventional drilling using pig calvaria, which consisted of thin cortical layer and dense cancellous bone. Piezoelectric technique showed the highest mean temperatures, positively correlated with longer osteotomies durations. Compared to our results, the temperatures recorded in this study are, on the whole, lower (38.0 \pm 2.7 with $100-200 \mathrm{~g}$ load applied). This is likely to be related to the different tip (IM3, Mectron Medical Technology) and cooling system utilized. Moreover, the $2 \mathrm{~mm}$ distance between the thermal probe and the implant site may have discarded sudden temperature variations.

In our study, a significantly longer drilling time was observed in the cortical samples. Higher mean temperatures observed in the cortical samples may therefore be the 
overall result of compact bone resistance, prolonged drilling time, and hence enhanced heat production due to frictional forces. In order to comprehend bone thermal behavior, its structural and mechanical properties should also be taken into account. Bone can be described as a composite material made of different structures, hierarchically organized on different dimensional scales [31]. From this perspective, the distinction between cortical and trabecular bone takes into account only the macrostructural level. Nevertheless, even considering pure cortical bone, heterogeneity can arise from variable microstructural parameters such as porosity and percentage mineralization [32]. Thus, for instance, in analyzing the mechanical properties of compact bone, Currey [33] demonstrated a strong positive relationship between Young's modulus and both calcium content and volume fraction. It is likely that such heterogeneity will be reflected in thermal behavior, with more evident effects in trabecular bone where substantial variations are apparent even at the macroscopic level. As suggested by Davidson and James [26], thermal properties such as conductivity and heat capacity not only depend on the intrinsic properties of the material itself, but are also influenced by its structural organization. A comprehensive study of the interrelationship between mechanical and thermal properties of bone has however yet to be conducted.

As a result, some authors propose use of artificial bone specimens to overcome the limitations imposed by traditional ex vivo bone samples $[34,35]$. According to these authors, synthetic bone specimens provide homogeneous characteristics together with thermal conductivity similar to that of human bone.

It is interesting finally to note that the influence of bone sample characteristics has rarely been considered of pivotal importance when dealing with the rotating technique [36]. This derives from the different "sensitivity" of rotating and ultrasonic techniques with respect to bone features. The mechanical energy applied in rotating techniques is much greater than the mechanical resistance of the finest bone characteristics, so that their influence on temperature may be ignored by a measuring apparatus, whereas ultrasonic vibrations provide a "gentler" action, involving less local delivery of mechanical energy. As a result, even the finest bone structures possess nonnegligible effects in terms of heat generation and measurement.

This preliminary study has certain limitations. First, even though the osteotomies were performed by a single expert operator with a real time pressure displaying device, this does not represent complete standardization of working conditions. In addition, recording and analysis pressure data during bone drilling might reveal more precise correlations between applied load and temperature rise.

\section{Conclusion}

Temperature rise during bone drilling is a very complex phenomenon affected by many variables. Although some operator-related variables can be minimized (though not totally eliminated), less can be done to exclude variabilities resulting from bone samples. Pure cortical bone samples were characterized by lower temperature variability during in vitro tests; however they do not represent actual clinical conditions. Differently, corticocancellous samples are a better simulation of in vivo conditions but were affected by greater variability of results. Cortical samples also showed longer osteotomies duration and higher mean temperatures. Given the difficulty in controlling some of the bone-related variables that are likely to be important factors in heat generation, the lack of standardization of technique- and operator-related factors may lead to increased variability in temperatures and risk of overheating.

\section{Conflict of Interests}

The authors declare that there is no conflict of interests regarding the publication of this paper.

\section{Acknowledgments}

The authors acknowledge Dr. Daniele Di Nezio for the graphic illustrations. Mectron Medical Technology (Carasco, Italy) is also acknowledged for the technical support to the research.

\section{References}

[1] L. S. Matthews and C. Hirsch, "Temperatures measured in human cortical bone when drilling," The Journal of Bone \& Joint Surgery-American Volume, vol. 54, no. 2, pp. 297-308, 1972.

[2] G. Cordioli and Z. Majzoub, "Heat generation during implant site preparation: an in vitro study," The International Journal of Oral \& Maxillofacial Implants, vol. 12, no. 2, pp. 186-193, 1997.

[3] K. Jo, K. Yoon, K. Park et al., “Thermally induced bone necrosis during implant surgery: 3 case reports," Journal of the Korean Association of Oral and Maxillofacial Surgeons, vol. 37, no. 5, pp. 406-414, 2011.

[4] A. C. G. D. S. Carvalho, T. P. Queiroz, R. Okamoto, R. Margonar, I. R. Garcia Jr., and O. Magro Filho, "Evaluation of bone heating, immediate bone cell viability, and wear of high-resistance drills after the creation of implant osteotomies in rabbit tibias," The International Journal of Oral \& Maxillofacial Implants, vol. 26, no. 6, pp. 1193-1201, 2011.

[5] C. Rouiller and G. Majno, "Morphological and chemical studies of bones after the application of heat," Beiträge zur Pathologischen Anatomie und zur Allgemeinen Pathologie, vol. 113, no. 1, pp. 100-120, 1953.

[6] L. S. Matthews, C. A. Green, and S. A. Goldstein, "The thermal effects of skeletal fixation-pin insertion in bone," The Journal of Bone \& Joint Surgery - American Volume, vol. 66, no. 7, pp. 10771083, 1984.

[7] P. Trisi, M. Berardini, A. Falco, M. P. Vulpiani, and L. Masciotra, "Effect of 50 to $60^{\circ} \mathrm{C}$ heating on osseointegration of dental implants in dense bone: an in vivo histological study," Implant Dentistry, vol. 23, no. 5, pp. 516-521, 2014.

[8] A. R. Eriksson and T. Albrektsson, "Temperature threshold levels for heat-induced bone tissue injury: a vital-microscopic study in the rabbit," The Journal of Prosthetic Dentistry, vol. 50, no. 1, pp. 101-107, 1983. 
[9] Y. Reingewirtz, S. Szmukler-Moncler, and B. Senger, "Influence of different parameters on bone heating and drilling time in implantology," Clinical Oral Implants Research, vol. 8, no. 3, pp. 189-197, 1997.

[10] R. A. Delgado-Ruiz, D. Sacks, A. Palermo, J. L. Calvo-Guirado, C. Perez-Albacete, and G. E. Romanos, "Temperature and time variations during osteotomies performed with different piezosurgical devices: an in vitro study," Clinical Oral Implants Research, 2015.

[11] U. T. Da Silva Neto, J. C. Joly, and S. A. Gehrke, "Clinical analysis of the stability of dental implants after preparation of the site by conventional drilling or piezosurgery," British Journal of Oral and Maxillofacial Surgery, vol. 52, no. 2, pp. 149-153, 2014.

[12] T. Vercellotti, "Technological characteristics and clinical indications of piezoelectric bone surgery," Minerva Stomatologica, vol. 53, no. 5, pp. 207-214, 2004.

[13] M. Simonetti, G. Facco, F. Barberis et al., "Bone characteristics following osteotomy surgery: an in vitro SEM study comparing traditional Lindemann drill with sonic and ultrasonic instruments," Poseido, vol. 1, no. 3, pp. 187-194, 2013.

[14] T. Vercellotti, M. L. Nevins, D. M. Kim et al., "Osseous response following resective therapy with piezosurgery," The International Journal of Periodontics \& Restorative Dentistry, vol. 25, no. 6, pp. 543-549, 2005.

[15] C. Stacchi, T. Vercellotti, L. Torelli, F. Furlan, and R. Di Lenarda, "Changes in implant stability using different site preparation techniques: twist drills versus piezosurgery. A single-blinded, randomized, controlled clinical trial," Clinical Implant Dentistry and Related Research, vol. 15, no. 2, pp. 188-197, 2013.

[16] L. Lamazza, D. Laurito, M. Lollobrigida et al., "Identification of possible factors influencing temperatures elevation during implant site preparation with piezoelectric technique," Annali di Stomatologia, vol. 5, no. 4, pp. 115-122, 2015.

[17] G. Augustin, S. Davila, K. Mihoci, T. Udiljak, D. S. Vedrina, and A. Antabak, "Thermal osteonecrosis and bone drilling parameters revisited," Archives of Orthopaedic and Trauma Surgery, vol. 128, no. 1, pp. 71-77, 2008.

[18] S. K. Mishra and R. Chowdhary, "Heat generated by dental implant drills during osteotomy-a review," The Journal of Indian Prosthodontic Society, vol. 14, no. 2, pp. 131-143, 2014.

[19] S. H. Tehemar, "Factors affecting heat generation during implant site preparation: a review of biologic observations and future considerations," The International Journal of Oral \& Maxillofacial Implants, vol. 14, no. 1, pp. 127-136, 1999.

[20] J. D. Currey, J. W. Pitchford, and P. D. Baxter, "Variability of the mechanical properties of bone, and its evolutionary consequences," Journal of the Royal Society Interface, vol. 4, no. 12, pp. 127-135, 2007.

[21] M. J. Yacker and M. Klein, "The effect of irrigation on osteotomy depth and bur diameter," The International Journal of Oral \& Maxillofacial Implants, vol. 11, no. 5, pp. 634-638, 1996.

[22] G. Augustin, S. Davila, T. Udiljak, D. S. Vedrina, and D. Bagatin, "Determination of spatial distribution of increase in bone temperature during drilling by infrared thermography: preliminary report," Archives of Orthopaedic and Trauma Surgery, vol. 129, no. 5, pp. 703-709, 2009.

[23] M. B. Abouzgia and D. F. James, "Temperature rise during drilling through bone," The International Journal of Oral \& Maxillofacial Implants, vol. 12, no. 3, pp. 342-353, 1997.

[24] S. Karmani, "The thermal properties of bone and the effects of surgical intervention," Current Orthopaedics, vol. 20, no. 1, pp. 52-58, 2006.
[25] R. K. Pandey and S. S. Panda, "Drilling of bone: a comprehensive review," Journal of Clinical Orthopaedics and Trauma, vol. 4, no. 1, pp. 15-30, 2013.

[26] S. R. H. Davidson and D. F. James, "Measurement of thermal conductivity of bovine cortical bone," Medical Engineering \& Physics, vol. 22, no. 10, pp. 741-747, 2000.

[27] F. Karaca, B. Aksakal, and M. Kom, "Influence of orthopaedic drilling parameters on temperature and histopathology of bovine tibia: an in vitro study," Medical Engineering \& Physics, vol. 33, no. 10, pp. 1221-1227, 2011.

[28] B. C. Sener, G. Dergin, B. Gursoy, E. Kelesoglu, and I. Slih, "Effects of irrigation temperature on heat control in vitro at different drilling depths," Clinical Oral Implants Research, vol. 20, no. 3, pp. 294-298, 2009.

[29] A. Rashad, A. Kaiser, N. Prochnow, I. Schmitz, E. Hoffmann, and P. Maurer, "Heat production during different ultrasonic and conventional osteotomy preparations for dental implants," Clinical Oral Implants Research, vol. 22, no. 12, pp. 1361-1365, 2011.

[30] F. Stelzle, C. Frenkel, M. Riemann, C. Knipfer, P. Stockmann, and E. Nkenke, "The effect of load on heat production, thermal effects and expenditure of time during implant site preparation-an experimental ex vivo comparison between piezosurgery and conventional drilling," Clinical Oral Implants Research, vol. 25, no. 2, pp. 140-148, 2014.

[31] J.-Y. Rho, L. Kuhn-Spearing, and P. Zioupos, "Mechanical properties and the hierarchical structure of bone," Medical Engineering \& Physics, vol. 20, no. 2, pp. 92-102, 1998.

[32] T. M. Keaveny, E. F. Morgan, and O. C. Yeh, "Bone mechanics," in Standard Handbook of Biomedical Engineering and Design, M. Kutz, Ed., pp. 8.1-8.23, McGraw Hill, New York, NY, USA, 2003.

[33] J. D. Currey, "The effect of porosity and mineral content on the young's modulus of elasticity of compact bone," Journal of Biomechanics, vol. 21, no. 2, pp. 131-139, 1988.

[34] G. D. Strbac, K. Giannis, E. Unger, M. Mittlböck, G. Watzek, and W. Zechner, "A novel standardized bone model for thermal evaluation of bone osteotomies with various irrigation methods," Clinical Oral Implants Research, vol. 25, no. 5, pp. 622-631, 2014.

[35] G. Sannino, P. Capparé, E. F. Gherlone, and A. Barlattani, "Influence of the implant drill design and sequence on temperature changes during site preparation," The International Journal of Oral \& Maxillofacial Implants, vol. 30, no. 2, pp. 351-358, 2015.

[36] G. Augustin, T. Zigman, S. Davila et al., "Cortical bone drilling and thermal osteonecrosis," Clinical Biomechanics, vol. 27, no. 4, pp. 313-325, 2012. 

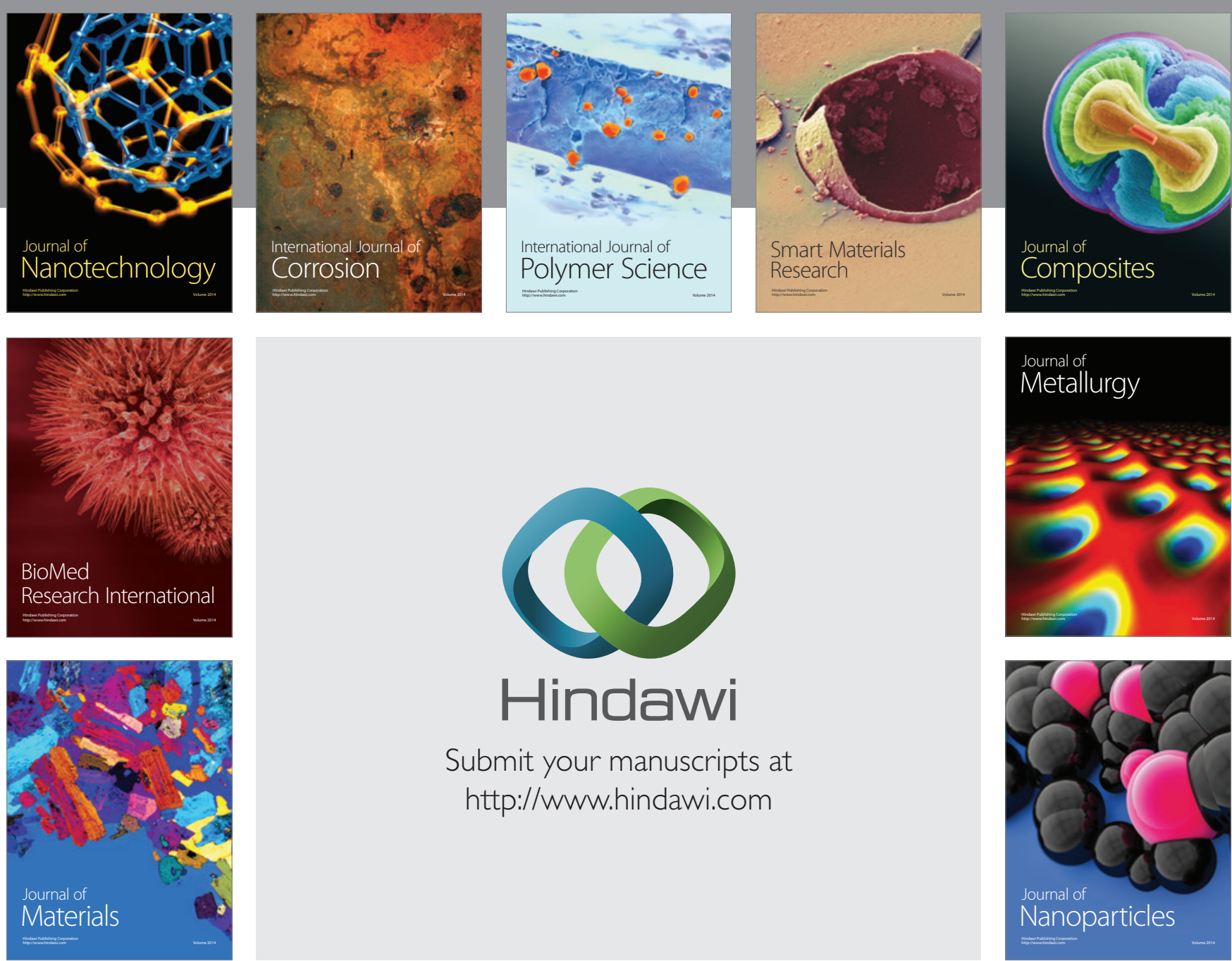

\section{Hindawi}

Submit your manuscripts at

http://www.hindawi.com

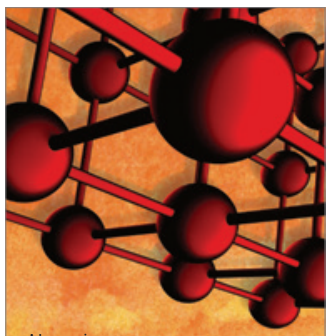

Materials Science and Engineering
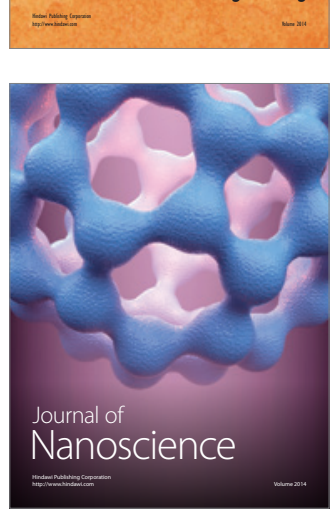
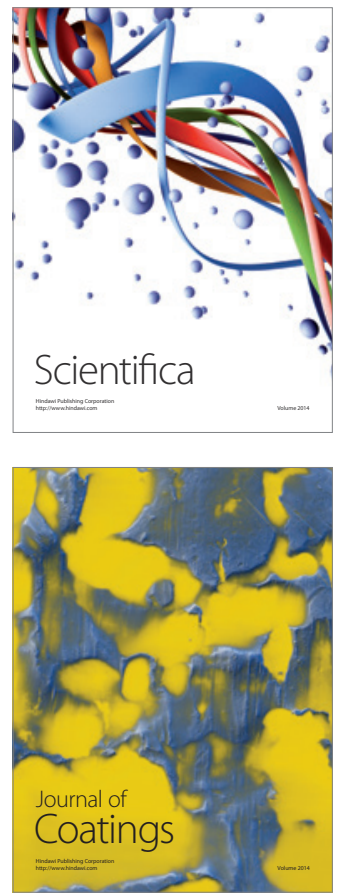
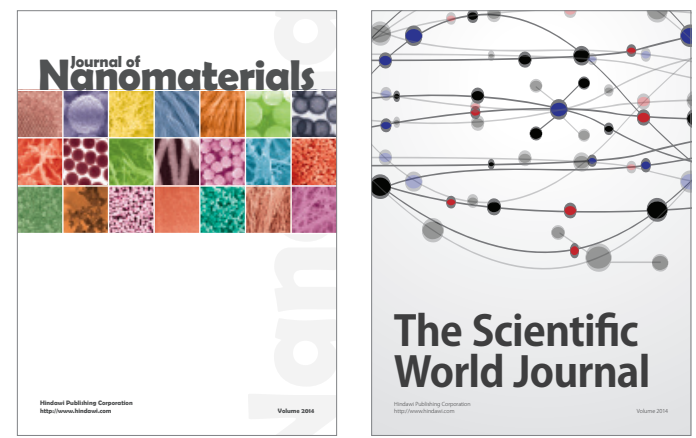

The Scientific World Journal
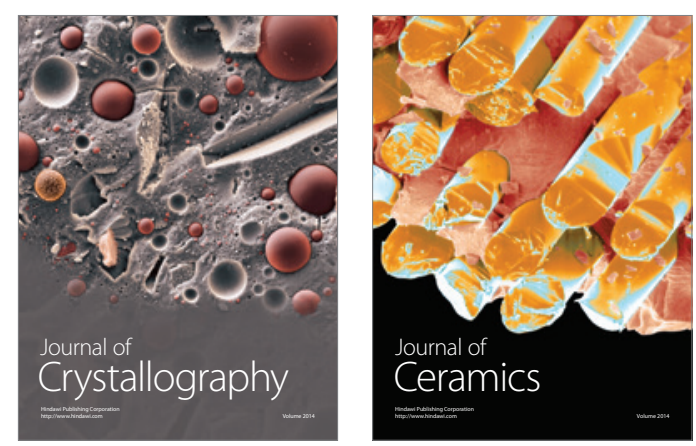
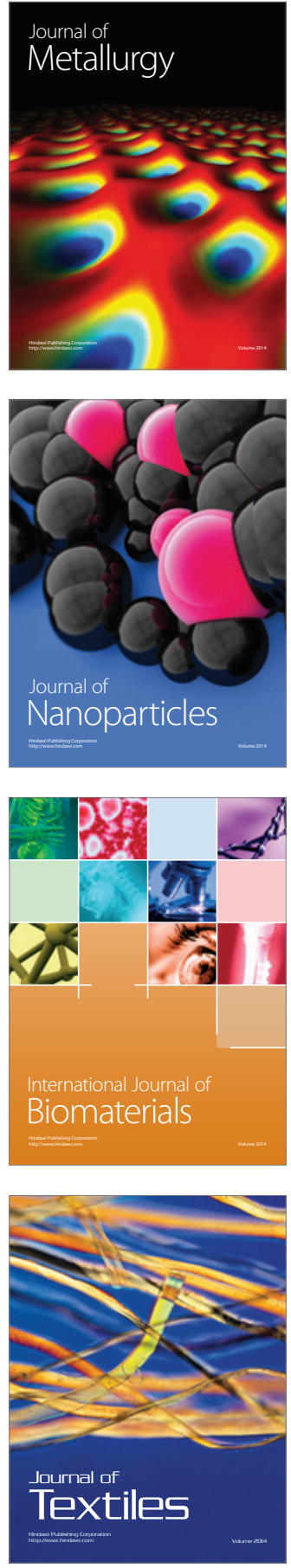